\title{
Bioavailability of Rifampicins Produced in Korea
}

\author{
Sang Jae Kim and Sung Chin Kim
}

The Korean Institute of Tuberculosis, The Korean National Tuberculosis Association, Seoul, Korea $=$ 國文抄錄 $=$

韓國產 Riampicin 製劑年 生物學的 利用効率

\author{
大韓結核協會 結核研究院 \\ 金劣 材·金 成 鎭
}

현재 國內에서 生產되어 市販되고있는 抗結核劑중에서 短期化學療法의 主軸을 이루고있는 rifampicin 製劑의 品質에 관해 조사한 결과 다음과 같은 결과를 얻었다.

시험된 모든 製劑가 偏光顯微鏡아래서 複屈折을 보여주었고 不純物含量은 N-oxide rifampicin이 比較標準製品 $\left(\operatorname{Rifadin}{ }^{\oplus}\right)$ 보다 다소 더 많은 양을 함유하고 있지만, 3-formylrifampicin, quinone rifampicin 및 25-desacetyl rifampicin 등은 許容限界濃度보다 훨씬 낮은 양이 檢出되었다.

6 명의 건강인 남자를 대상으로 1 回服用交叉法(single dose cross-over method)에 따라 조사한 결 과 4會社製品의 生物學的 利用効率 (bioavailability)은 서로 有意한 差異없이 모두 높은 血中濃度를 보 여주었고 대체로 服用 2시간후에 最高血中濃度에 도달하였다. 標準製品과 LP 1이 다른 두제품(LP 2 및 LP 3)보다 비록 심한 個體差에 따른 큰 標準偏差로 有意한 差異라고 볼 수는 없지만, 平均 血中 濃度가 다소 높은데 이는 capsule 內 rifampicin 含量이 前者의 두 製劑가 後者의 두 製劑보다 높은 데 起因한다고 본다. 尿中濃度도 個體差가 심했으머 대체로 服藥後 2 3시 간에 最高濃度에 도달했다.

\section{Introduction}

Strong sterilizing power of rifampicin, particularly for the metabolically inert organisms in the lesions, enabled to shorten significantly the duration of tuberculosis chemotherapy without lowering the therapeuctic effect. ${ }^{1,2)}$ The Korean government has decided to include this drug even in the treatment regimens for the patients receiving anti-tuberculous chemotherapy for the first time. Increased rifampicin-dependence of our tuberculosis chemotherapy program urged us to consider the quality of local drug products, because we have come to fully understand that the rifampicin preparations produced through the varying manufacturing processes have a different bioavailability mainly due to different physico-chemical properties of the solid state of rifampicin bulk, capusles and excipients.

The present study aimed at evaluation of bioavailability of local rifampicin products by single dose cross-over methed. Crystal morphology of rifampicin and contanmiation of related compounds were also investigated by polarizing microscopy and by thin layer chromatography.

\section{Materials and Methods}

\section{Rifampicin products tested:}

Three local products and a reference product, $\operatorname{rifadin}^{\otimes}$ (Lepetit) were used.

RMP RP $=$ Rifadin $^{\otimes}$, Gruppo Lepetit Spa, Milan, manufactured on April 6, 1979.

RMP LP 1=Rifodex ${ }^{\oplus}$, Chong Kun Dang Corp., manufactured on December 27, 1980.

RMP LP 2 =Rifampin, Yu Han Corp., Manufactu- 
red on December 13, 1980.

RMP LP $3=$ Rifadin, Kuk-Je Corp., manufactured

on November 25, 1980.

Pure rifampicin(reagent grade), 3-formylrifam$y \operatorname{cin}(3 \mathrm{f}), 25$-desacetyl rifampicin(Dr), N-oxide rifampicin(Nr) and quinone rifampicin(Qr) were kindly provided by Gruppo Lepetit Spa.

\section{Morphology of rifampicin crystals:}

Morphology of rifampicin crystals in a dosage form was observed by means of polarizing microscope.

\section{Analysis of related compounds:}

Related compounds in a dosage form of rifampicin products were analysed by thin layer chromatography. Test samples and reference compounds were dissolved in chloroform to become $10 \mathrm{mg} / \mathrm{ml}$. The standard solution(SM) was prepared by mixing $1.5 \%$ of quinone rifampicin and $0.5 \%$ each of 3 -formylrifamycin, 25-desacetyl rifampicin and $\mathrm{N}$-oxide rifampicin into rifampicin solution. Fourty microliter of test samples and standard solution were applied on a plate coated with $0.5 \mathrm{~mm}$ thick silicagel $60(\mathrm{pH} \mathrm{6.0)}$, and the plate was developed in chloroform-methanol $(9:$ 1) solvent. Separated components in test sample were compared with the corresponding compounds in standard solution.

\section{Bioavailability of rifampicin preparations in man:}

The relative single bioavailability of dosage form rifampicins from different manufacturers were compared with each other in a balanced cross-over fashion.

4.1 Six male volunteers took part in this study. Their ages were 25 to 41 and body weights, between 55 to $75 \mathrm{~kg}$. Clinical and laboratory examinations were performed one day before the drug administration. Their complete blood counts, blood sedimentation rates, crea tinine clearance, urinalysis, bilirubin, SGOT, SGPT and blood pressures showed normal values. None of the volunteers had an history of gastric ulcer, hepatitis, renal diseases, hypertension, heart disease, blood disorder, allergy, diabetes and hyperthyroidism.

Each volunteer took a single oral dose of $600 \mathrm{mg}$ rifampicin at 9 o'clock in the morning after an overnight fast. All six volunteers took all four preparations in four different days of study with three six-day intervals according to the balanced cross-over design (Table 1).

4.2 Blood samples were collected from all subjects at $1 / 2,1,2,3$ and 6 hours after each administration. The sera were separated from the blood specimens within 2-3 houurs and stored at $1-4^{\circ} \mathrm{C}$. Urine samples were also collected at $1 / 2,1,2$, $3,6,9$, and 24 hours post administration.

4.3 Microbiological assay of rifampicin in serum and urine samples: Serum and urine levels of rifampicin were measured by the agar diffusion method using Sarcina lutea ATCC 9341.

4.3.1 Plate preparation: The bacterial suspension of S. lutea was prepared by washing the slant culture incubated overnight at $33^{\circ} \mathrm{C}$, with $10 \mathrm{ml}$ of sterile saline and diluted until it had a transmittance of 70 to $80 \%$ at $650 \mathrm{~nm}$ with spectrophotometer using $1 \mathrm{~cm}$ thick cuvette against a

Table 1. Design for drug administraction

\begin{tabular}{|c|c|c|c|c|}
\hline \multirow[t]{2}{*}{ Volunteers } & \multicolumn{4}{|c|}{ Administration scheme(day) } \\
\hline & 1st & 2nd & 3 rd & 4th test \\
\hline 1 & $\mathrm{RP}$ & LP 1 & LP 2 & LP 3 \\
\hline 2 & RP & LP 1 & LP 2 & LP 3 \\
\hline 3 & LP 3 & $\mathrm{RP}$ & PL 1 & PL 2 \\
\hline 4 & LP 3 & $\mathrm{RP}$ & LP 1 & LP 2 \\
\hline 5 & LP 2 & LP 3 & $\mathrm{RP}$ & LP 1 \\
\hline 6 & LP 1 & LP 2 & LP 3 & $\mathrm{RP}$ \\
\hline
\end{tabular}

RP $=$ Lepetit Rifadin ${ }^{\otimes}, \mathrm{LP} 1=$ Rifodex $^{\otimes}, \mathrm{LP} 2=$ Rifampin, LP3=Kuk-Je Rifadin 
blank of normal saline. The bacterial suspension then was inoculated in molten medium cooled to $48 \sim 49^{\circ} \mathrm{C}$. The medium contained peptone $6 \mathrm{~g}$, enzymatic digest of casein $4 \mathrm{~g}$, yeast extract $3 \mathrm{~g}$, beef extract $1.5 \mathrm{~g}$, dextrose $1 \mathrm{~g}$, and agar $15 \mathrm{~g}$ in $1,000 \mathrm{ml}$ of distilled water, and $\mathrm{pH}$ had been adjusted to 6.5-6.6 after autoclaving at $15 \mathrm{lb}$ for 15 min. Eleven $\mathrm{ml}$ of inoculated medium was dispensed into a plate $(9 \mathrm{~cm}$ diameter $)$ and allowed it to harden into a even surface of uniform depth.

4.3.2. Assay: Small quantity of pure rifampicin was weighed out and dissolved in methanol. The solution was diluted with phosphate buffer $\mathrm{pH} 7.0$ $\left(\mathrm{KH}_{2} \mathrm{PO}_{4} 3.52 \mathrm{~g}, \mathrm{Na}_{2} \mathrm{HPO}_{4} 12 \mathrm{H}_{2} \mathrm{O} 14.62 \mathrm{~g}\right.$ in 1,000 $\mathrm{ml}$ of distilled water) to become $0.2,0.6$ and 1.8 $\mathrm{mcg} / \mathrm{ml}$. Serum samples were diluted in $0,5,10$ or 20 times in $\mathrm{pH} 7.0$ phosphate buffer, depending on the collection time after drug administration. Urine samples were diluted in $10,50,100,200$ or 300 times depending on the collection time. Five inoculated plates were used for two different dilutions of each sample. Disks ( $1 \mathrm{~mm}$ thick, $6.5 \mathrm{~mm}$ in diameter) were soaked in test and standard durg solutions and placed on plates as follows:

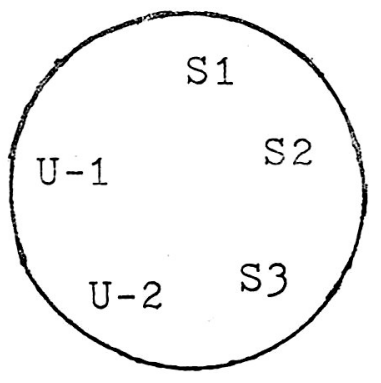

$\mathrm{S}_{1}, \mathrm{~S} 2, \mathrm{~S} 3=$ standard $\mathrm{d}$ ug suiutions, $0.2,0.6$ and $1.8 \mathrm{mcg} / \mathrm{ml}$ respectively

$\mathrm{U}-1, \mathrm{U}-2=$ two different dilutions of test sample

The diameters of inhibitory zones produced by standard and sample solutions were measured after overnight incubation in an inverted position at $33^{\circ}$ C. The potency for each sample was calulated using the following formula.

Potency $\left.=\operatorname{antilog}\left(\frac{\mathrm{U}-1 / 3(\mathrm{~S} 1+\mathrm{S} 2+\mathrm{S} 3)}{\frac{(\mathrm{S} 3-\mathrm{S} 1)}{2 \times \log \mathrm{R}}}+\log \mathrm{S} 2\right)\right)$ $\times$ dil.f.

\section{Where}

S 1, S 2, S $3=$ sums of the 5 inhibitory zones produced by standard drug solution, S 1, S 2 and $\mathrm{S} 3$. $\mathrm{U}=$ sums of the 5 measures of the inhibitory zones produced by serum or urine sample. Dil.f.= dilution factor relevant to the sample dilution whose inhibitory zones have been measured. Log S $2=$ logarithm (base 10) of the mean point concentration of standard curve(in this case, $\log 6$ ). $\log R=\log a-$ rithm of the ratio between two adjacent dilutions of the standard (in this case, log 3 ). If sum of the 5 measures of the inhibitory zones produced by serum or urine dilutions, was larger than that of highest concentration of the standard or smaller than that of lowest concentration of the standard, the test had been repeated using proper serum or urine dilutions.

\section{Analysis of content uniformity:}

Content of whole capsule(150 or $300 \mathrm{mg}$ ) was dissolved in methanol and then diluted phosphate buffer $\mathrm{pH} 7.0$, to become $32 \mathrm{mcg} / \mathrm{ml}$, on the basis of amount of content as indicated. Ten capsules of each manufacturer's preparations had been tested. Standard solutions were prepared with pure rifampicin and their concentrations were $64,32,16$ and $8 \mathrm{mcg} / \mathrm{ml}$. Optical density of standard and sample solutions was measured by spectrophotometer at $475 \mathrm{~nm}$ and rifampicin content of each capsule was calculated by comparing ODs of samples with those of standards.

\section{Results}

Rifampicin crystals of all four preparation showed a birefringency under polarizing microscope even if shape, color and size of crystals were slightly different in some product.

Thin layer chromatography showed that four major related compounds analysed were deceted in all preparations, but their contents were within acceptable range as seen in fig. 1. Much lower concentrations of 3 -formyl rifamycin, 25-desacetyl rifampicin, and quinone rifampicin, were observed 
Table 2. Mean blood levels and standard deviations after oral administration of $600 \mathrm{mg}$ rifampicin RP, LP 1, LP 2 and LP 3.

\begin{tabular}{lccccc}
\hline \hline Test Products & \multicolumn{5}{c}{ Blood levels in mcg/ml after } \\
\cline { 2 - 5 } & $1 / 2 \mathrm{hr}$. & $1 \mathrm{hr}$. & $2 \mathrm{hrs}$. & $3 \mathrm{hrs}$. & $6 \mathrm{hrs.}$ \\
\hline RP & $2.9 \pm 2.4$ & $14.4 \pm 6.2$ & $15.9 \pm 3.1$ & $14.5 \pm 2.8$ & $7.5 \pm 1.2$ \\
LP 1 & $6.4 \pm 3.9$ & $14.2 \pm 5.6$ & $16.0 \pm 4.7$ & $11.6 \pm 2.3$ & $6.9 \pm 1.3$ \\
LP 2 & $3.2 \pm 4.2$ & $13.1 \pm 3.8$ & $13.8 \pm 3.1$ & $11.0 \pm 2.0$ & $6.5 \pm 0.5$ \\
LP 3 & $3.2 \pm 3.0$ & $9.1 \pm 2.9$ & $14.2 \pm 4.3$ & $11.2 \pm 2.6$ & $7.4 \pm 1.9$ \\
\hline
\end{tabular}

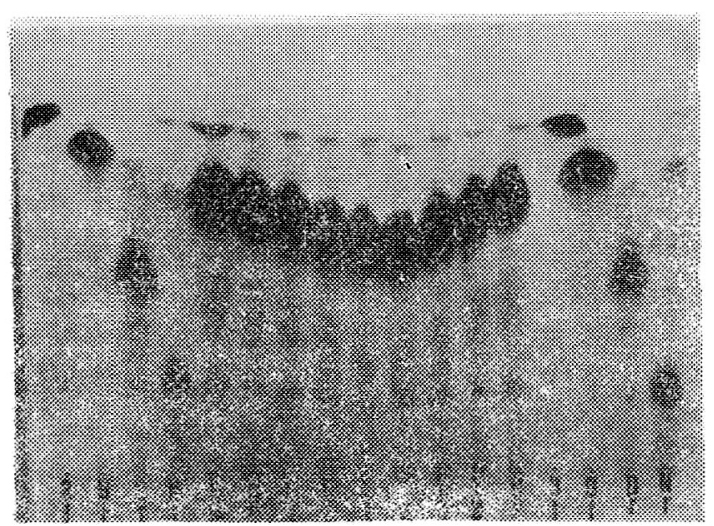

Fig. 1. Thin layer chromatographic analysis of four rifampicin products.
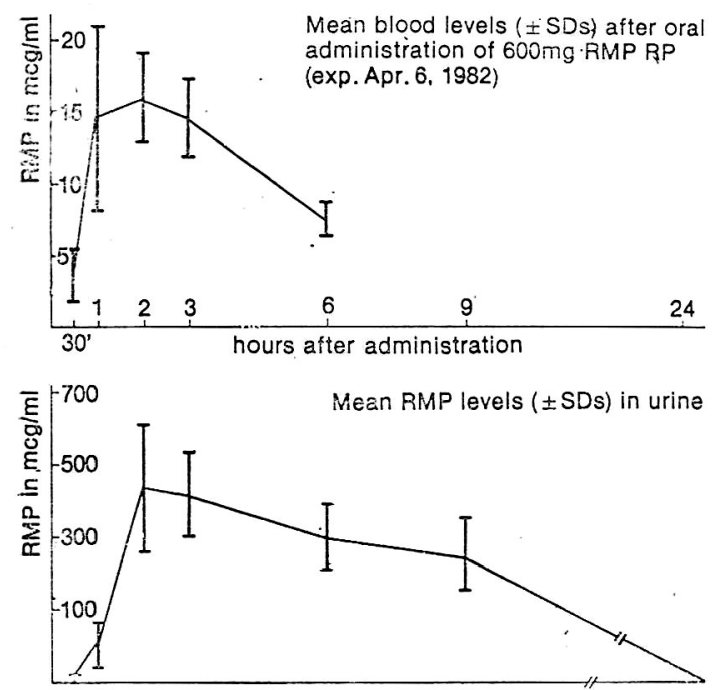

Fig. 2. Mean blood and urine levels $( \pm S D)$ after single oral administration of $600 \mathrm{mg}$ Rifadin $^{\circledast}(\mathrm{RP})$ in all four preparations than those in the standard. $\mathrm{N}$-oxide rifampicin, however, was contained in relatively higher concentration in three local products (LP 1, 2, \& 3) when it was compared with RP and the standard.

Investigation on bioavailability of rifampicin in Korean men after single oral administration showed that no significant difference in mean peak blood levels was observed between four preparations as seen in table 2 and figs. 2-6. Peak blood levels and the time to attain these levels after drug administration vary between individuals(Fig. 7) and between tests. Peak blood levels were usually obtained at two hours post administation in all four preparations. At half an hour after administration, LP 1 showed relatively
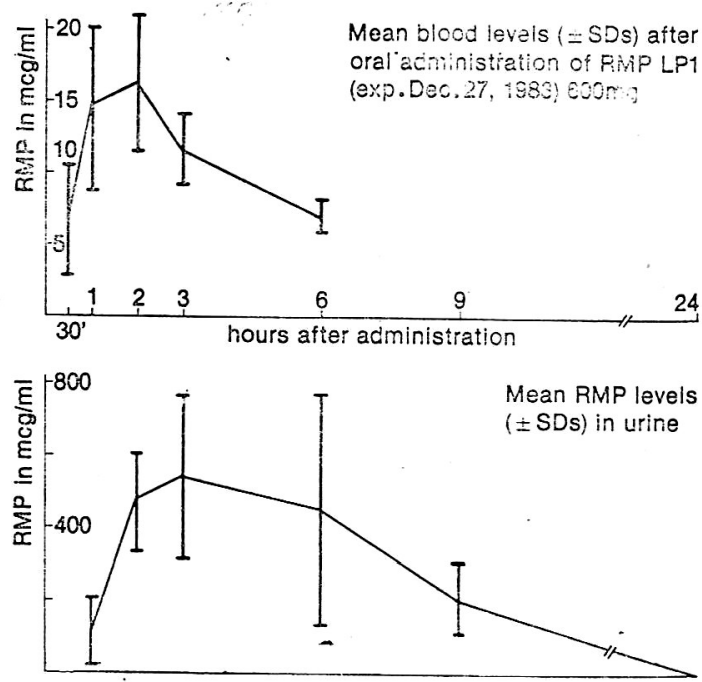

Fig. 3. Mean blood and urine levels $( \pm \grave{D} \bar{D})$ after single oral administration of $600 \mathrm{mg}$ Rifo$\operatorname{dex}^{\oplus}(\mathrm{LP} 1)$ 

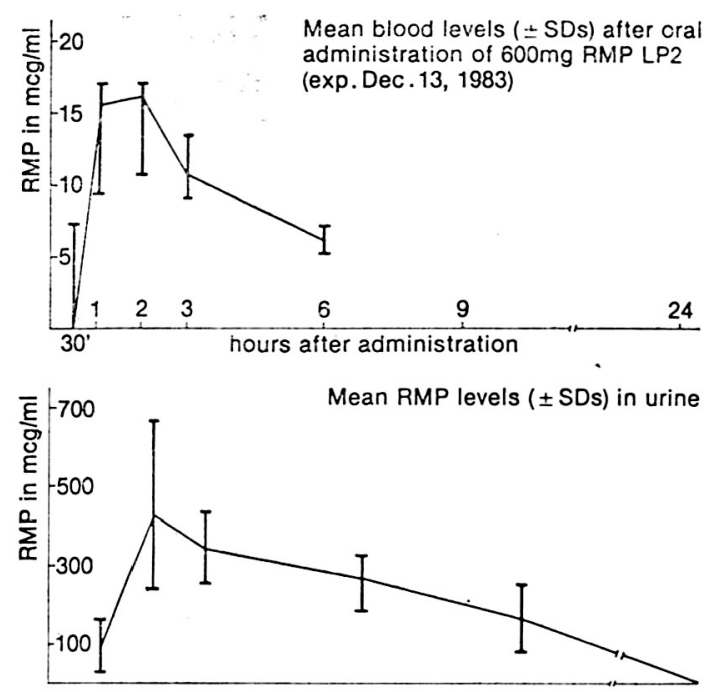

Fig. 4. Mean blood and urine levels $( \pm S D)$ after single oral administration of $600 \mathrm{mg}$ Rifa$\operatorname{mpin}(\mathrm{LP}$ 2)
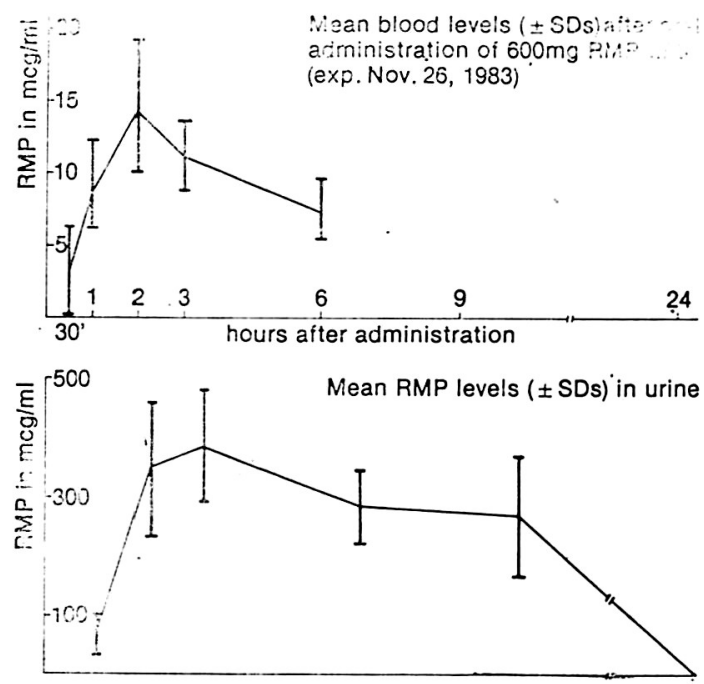

Fig. 5. Mean blood and urine levels $( \pm S D)$ after single oral administration of $600 \mathrm{mg}$ Rifadin (LP 3)

higher concentration than the others although the differences were not statistically significant. Relatively low level was obtained with LP 3 at one hour after administration as compared with the others, and mean peak blood levels attained at

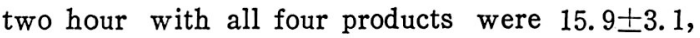
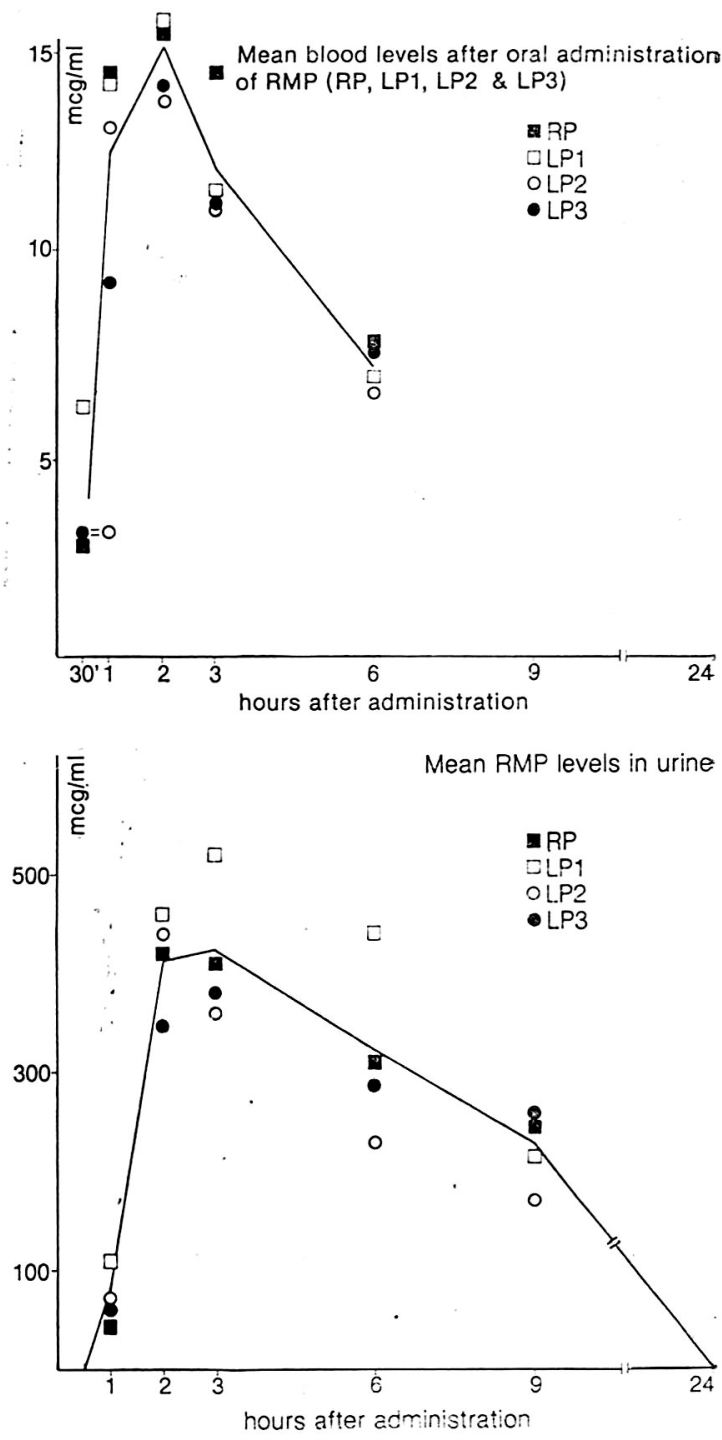

Fig. 6. Summary of mean blood and urine levels of four test preparations.

16. $0 \pm 4.7,13.8 \pm 3.1$ and $14.2 \pm 4.3 \mathrm{mcg} / \mathrm{ml}$ with RP, LP 1, LP 2 and LP 3 respectively. At three hour, blood level of RP remained in higher concentration than those of other produrcts. Mean blood levels at six hour were $6.5 \sim 7.5 \mathrm{mcg} / \mathrm{ml}$, indicating 32 to 150 times higher than in vitro minimal inhibitory concentration $(0.05-0.2 \mathrm{mcg} / \mathrm{ml})$ against M. tuberculosis.

Mean blood levels between volunteers vary greatly to one another and it seemed to be in 
inverse proportion to body weight as seen in fig. 7.

Rifampicin in urine was detected at half an hour after administration, but peak levels attained usually at two to three hour as seeen in table 3 and figs.
2-7. No statistically significant differences in mean peak urine levels and the time to attain it, had been noticed between preparations and between individuals. The peak urine levels of RP, LP 1, LP 2

Table 3. Mean urine levels and standard deviations after oral administration of $600 \mathrm{mg}$ rifampicin RP, LP $1, \operatorname{LP} 2$ and LP 3

\begin{tabular}{lrccccc}
\hline \hline Test products & \multicolumn{5}{c}{ Urine levels in $\mathrm{mcg} / \mathrm{ml}$ after } \\
\cline { 2 - 6 } & \multicolumn{1}{c}{1} & \multicolumn{1}{c}{2} & 3 & 6 & 9 & $24 \mathrm{hrs}$. \\
\hline RP & $53 \pm 30$ & $423 \pm 178$ & $410 \pm 107$ & $310 \pm 66$ & $251 \pm 100$ & $7 \pm 10$ \\
LP 1 & $114 \pm 95$ & $460 \pm 147$ & $527 \pm 231$ & $443 \pm 319$ & $214 \pm 104$ & $9 \pm 7.4$ \\
LP 2 & $73 \pm 59$ & $439 \pm 208$ & $359 \pm 105$ & $255 \pm 74$ & $172 \pm 102$ & $6 \pm 8$ \\
LP 3 & $96 \pm 37$ & $348 \pm 107$ & $384 \pm 92$ & $285 \pm 60$ & $264 \pm 105$ & $6 \pm 5$ \\
\hline
\end{tabular}
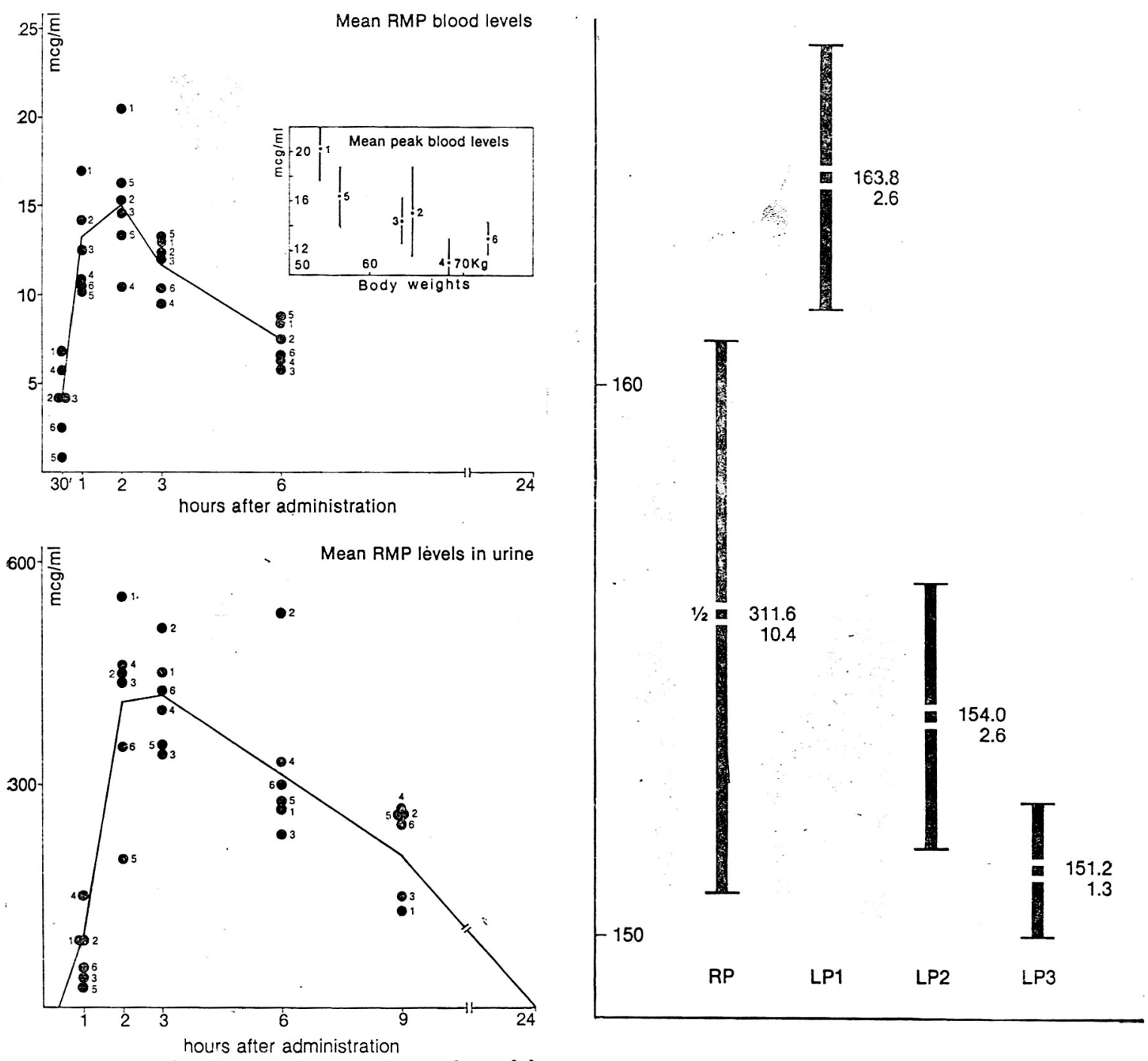

Fig. 7. Mean blood and urine levels of rifampicin in 6 volunteers.

Fig. 8. Content uniformity of $\pm M P$ capsules $(\mathrm{mg})$ 
and LP 3 were $423 \pm 178 \mathrm{mcg} / \mathrm{ml}$ at two hours after administration, $527 \pm 231 \mathrm{mcg} / \mathrm{ml}$ at three hour, 439 $\pm 208 \mathrm{mcg} / \mathrm{ml}$ at two hour and $384 \pm 92 \mathrm{mcg} / \mathrm{ml}$ at three hour respectively. Less than $20 \mathrm{mcg} / \mathrm{ml}$ of rifampicin was detected in urine at 24 hour post administration.

Study on content uniformity of rifampicin capsules showed that RP contained $311.6 \pm 10.4 \mathrm{mg} /$ capsule and three local products, LP 1, LP 2, and LP 3,

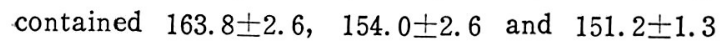
$\mathrm{mg} /$ capsule respectively as seen in fig. 8 .

\section{Discussion}

It has been well known that lipophilicity and less ionic dissociation of rifampicin molecules facilitated this powerful antibiotic to be easily absorbed through gastrointestinal tract and diffused in tissues, ${ }^{3,4}$.) However, rifampicin prerarations produced through varying manufacturing processes, which bring about different physicochemical properties of rifampicin crystals, capsules and excipients, render different bioavailability. These situation urged us to investigate on bioavailability of local products as our national tuberculosis chemotherapy program increasingly depend on rifampicin.

U.S. Pharmacopoeia-1980 requires birefringency of rifampicin crystals under polarizing microscope 5). This study revealed that all local products(LP1, $2, \& 3)$ and the reference product(RP) showed a birefringency under polarizing microscope.

Some crystals in LP 3, however, showed somewhat longer and darker color. Contamination of related compounds in dosage form of local rifampicin products was below the ranges which British or Europian pharmacopoeia-1980 prescribed.6,7) But relatively higher amount of $\mathrm{N}$-oxide rifampicin was contained in local products than the reference product $(\mathrm{RP})$ and the standard in which it contained $0.5 \%$. Therefore, some efforts must be made to reduce the amount of $\mathrm{N}$-oxide rifampicin contamination in local products.

Study on bioavailability of local and the reference rifampicin products showed that there was no statistically significant differences in mean peak blood level and time when peak level was reached. Great variation was noticed between individuals. Body weight seemed to have infulenced to the diffetences in mean peak llood level. This finding was contrary to some other report in which no direct relationship was observed between body weight and mean peak blood levels. ${ }^{8)}$ Peak blood levels of all four products were obtained at two hour after administration and it remained 32 to 150 times higher concentration than the minimal inhibitory concentration to $M$. tuberculosis, up to six hours. Statistically insignificant differences in blood levels were noticed between LP 3 and RP or LP 1 and it might had been resulted from different contents of rifampicin in capsules as shown in fig. 8. It has been reported that approximately $26 \%$ of rifampicin administered excreted in urine.5) We could detect rifampicin in urine as early as half an hour after administration, but maximum levels were observed at two to three hours after. There were also great variations between individuals and between tests.

\section{Summary}

A study on the quality of rifampicin produced in Korea was made by comparing with that of the reference product, rifadin ${ }^{\circledast}$ (Lepetit).

Rifampicin crystals in a dosage form of local products showed birefringency under polarizing microscope. Contamination of related compounds in local rifampicin products was not out of the accptable range, although contamination of $\mathrm{N}$-oxide rifampicin exceeded $0.5 \%$ in the standard and that of reference product. Mean peak blood levels of the reference and local products in Korean men were not statistically different from one to another and they were reached at two hour after administration. More than $5.6 \mathrm{mcg} / \mathrm{ml}$ of rifampicin was retained in serum up to six hour post administration. Urine rifampicin levels were variable between the subjects, and the peak levels were reached at two to three hour after administration. 


\section{REFERENCES}

1) Fox, W: Whither short-course chemotherapy, Br J Dis Chest, 75:331-357, 1981.

2) Mitchison, DA: Basic mechanisms of chemotherapy, Chest, 76:771-181, 1979.

3) Curci, G, Minni, A et Iodice, F: Quelques consideration sur la pharmacocinetique, Acta Tuberc pneumol belg, 60:276-287, 1969.

4) Gallo, GG and Radaelli, P: Rifampin, In Florey,
$K(E d)$, Analytical profiles of drug substances. Vol V, Academic Press, New York, San Francisco, London, 1976, p504.

5) US Pharmacopoeia 1980: Rifampin, p 1384.

6) Biritish Pharmacopoeia 1980: Rifampicinum, p 391.

7) Europian Pharmacopoeia 1980: Rifampicinum, p 52.

8) Verbist, L. 'Rifampicin blood levels in man, Acta tuberc pneumol belg, 60:288-298, 1969. 